\title{
Diagnosis and management of hyperglycemic emergencies
}

\author{
Niyutchai Chaithongdi ${ }^{1}$, Jose S. Subauste ${ }^{1,2}$, Christian A. Koch ${ }^{1,2}$, Stephen A. Geraci ${ }^{3}$ \\ ${ }^{1}$ Division of Endocrinology, Department of Medicine, University of Mississippi School of Medicine; ${ }^{2}$ Medical Service, \\ G.V. (Sonny) Montgomery VA Medical Center Jackson, MS; ${ }^{3}$ Department of Medicine, University of Mississippi School \\ of Medicine, Jackson, MS
}

\begin{abstract}
This article is aimed at providing a practical up-to-date review of the precipitating factors, diagnosis, management and secondary prevention of hyperglycemic emergencies (diabetic ketoacidosis (DKA) and hyperglycemic hyperosmolar state (HHS) to assist critical care physicians and hospitalists caring for these patients. Limitations of various guidelines include implementation in settings with an infrastructure different from that specified in the guidelines of a respective country, state, region or community. Appropriate individualized acute management of these conditions typically results in satisfactory clinical outcomes and may decrease the mortality rate from up to $20 \%$ in type 2 diabetics with hyperglycemic hyperosmolar state vs less than $2 \%$ in patients with DKA. DKA may be the first manifestation of type 1 diabetes and can also occur in type 2 diabetics depending on the state of insulin sufficiency/secretion. For type 1 diabetics, the transition period from adolescence to adulthood is particularly critical to prevent repetitive hospital admissions. Hyperglycemic emergencies are usually preventable but do depend on patient compliance and adherence as well as medical infrastructure. Patients of all ages should be both appropriately educated and assured continuous access to health care to prevent recurrences of these conditions.
\end{abstract}

Key words: Diabetes mellitus, Hyperglycemia, Hyperosmolar state, Ketoacidosis, Treatment

\section{INTRODUCTION}

Diabetic ketoacidosis (DKA) and the hyperglycemic hyperosmolar state (HHS) are life-threatening manifestations of decompensated diabetes mellitus and account for more than 120,000 hospital admis-

\footnotetext{
Corresponding Authors:

Niyutchai Chaithongdi MD and Prof. Dr. med. habil. Christian A. Koch, Division of Endocrinology, University of Mississippi Medical Center, 2500 N. State Str, Jackson, MS 39216, Tel.: 601-984-5495, Fax: 601-984-5789, E-mail: ton.nchaitho@ gmail.com \& ckoch@umc.edu

Received 23-07-11, Revised 15-08-11, Accepted 10-09-11
}

sions per year in the United States, based on data from 2005, compared to more than 62,000 hospital admissions per year in $1980 .{ }^{1}$ With regard to HHS, the rate of hospital admissions is lower and is less than $1 \%$ of all diabetic-related admissions. In the U.S., the costs for these hospital admissions, especially for DKA, are enormous and may easily exceed $\$ 15,000$ per patient hospitalization. These complications have been traditionally described as distinct entities, but patients can present with elements of both conditions in up to $30 \%$ of cases. ${ }^{2-4}$ Clinically, they differ by the severity of dehydration and whether or not ketosis 
and metabolic acidosis are present. Excess secretion of glucagon, catecholamines, cortisol and growth hormone promotes gluconeogenesis, glycogenolysis and lipolysis, resulting in DKA through a relative (type 2 diabetes) or absolute (type 1 diabetes) deficiency of insulin effect. ${ }^{5}$ These occur under stress, serious infection, trauma and cardiovascular emergencies. ${ }^{3}$ Characterized by severe hyperglycemia, hyperosmolarity and dehydration (but without apparent ketoacidosis), ${ }^{6} \mathrm{HHS}$ is typically seen in elderly type 2 diabetic patients and carries a higher mortality rate $(5-20 \%)$ compared to DKA $(<2 \%){ }^{7}$

\section{DIAGNOSIS}

\section{Clinical Presentation}

The symptoms of DKA begin rapidly, i.e. within hours of a precipitating event, while HHS develops insidiously over days or weeks. Hyperglycemia-associated symptoms common to both include polyuria, polydipsia, weight loss, increasing malaise, orthostatic dizziness and dry mucous membranes. Kussmaul respirations, acetone-scented breath, nausea, vomiting and abdominal pain (due to ketosis itself and correlating with the severity of acidosis) may occur in DKA. Late symptoms in severe cases of either disorder include confusion or stupor, which can progress to mental obtundation and coma. Early mental status changes may be observed in HHS patients who have a serum osmolality $>320 \mathrm{mmol} / \mathrm{kg}(320 \mathrm{mOsm} / \mathrm{kg})$, while a serum osmolality $>340 \mathrm{mmol} / \mathrm{kg}$ (320 mOsm $/ \mathrm{kg}$ ) usually results in obtundation or coma. ${ }^{6,8-11}$ Laboratory abnormalities in hyperglycemic emergencies are summarized in Table 1.

\section{Precipitating Factors}

A careful search for precipitating conditions should be made, as their correction contributes to improved outcomes and less frequent recurrences.

The most common illnesses precipitating DKA or HHS are infections, ${ }^{72,13}$ including viral syndromes, urinary tract infections, pelvic inflammatory disease, pneumonia, mucormycosis, malignant otitis externa (with pseudomonas aeruginosa), periodontal abscess and dental infection. Fever is frequently absent even with active infection; conversely, leukocytosis $\left(\geq 20,000 / \mathrm{mm}^{3}\right)$ and even leukemoid reactions may
Table 1. Laboratory diagnostic criteria for diabetic ketoacidosis and hyperglycemic hyperosmolar state on presentation $\ddagger$

\begin{tabular}{lcccc}
\hline & \multicolumn{3}{c}{ DKA } & \\
\cline { 2 - 4 } & Mild & Moderate & Severe & HHS \\
\hline $\begin{array}{l}\text { Glucose } \\
(\mathrm{mmol} / \mathrm{L})\end{array}$ & $>13.88$ & $>13.88$ & $>13.88$ & $>33.3$ \\
$\mathrm{pH}$ & $7.25-7.30$ & 7.0 to $<7.24$ & $<7.0$ & $>7.3$ \\
$\mathrm{HCO}_{3^{-}}$ & $15-18$ & 10 to $<15$ & $<10$ & $>15$ \\
$(\mathrm{mmol} / \mathrm{L})$ & & & & \\
$\mathrm{S}_{\text {osm }}$ & Variable & Variable & Variable & $>320$ \\
$(\mathrm{mmol} / \mathrm{kg})^{*}$ & & & & \\
Ketones & Positive & Positive & Positive & Small \\
Dehydration & $6 \mathrm{~L}$ & & & $9 \mathrm{~L}$ \\
Anion gap** & $>10$ & $>12$ & $>12$ & Variable \\
Mental status & Alert & $\begin{array}{c}\text { Alert/ } \\
\text { drowsy }\end{array}$ & $\begin{array}{c}\text { Stupor/ } \\
\text { coma }\end{array}$ & $\begin{array}{c}\text { Stupor/ } \\
\text { coma }\end{array}$ \\
\hline
\end{tabular}

*Effective serum osmolality $(\mathrm{mmol} / \mathrm{kg})=(2 \mathrm{x}$ sodium $)+($ glucose $)$

**Anion gap: $\left(\mathrm{Na}^{+}\right)-\left[\mathrm{Cl}^{-}+\mathrm{HCO}_{3}^{-}(\mathrm{mmol} / \mathrm{L})\right]$

DKA: diabetic ketoacidosis; HHS: hyperglycemic hyperosmolar state; $\mathrm{S}_{\text {osm }}$ : serum osmolality

¥Adapted from Kitabchi AE, Umpierrez GE, Miles JM, et al, 2009 Hyperglycemic crises in adult patients with diabetes. Diabetes Care 32:1335-1343

be present in the absence of infection. ${ }^{14}$ Cultures (urine, sputum, blood) should be obtained when infection is suspected. ${ }^{15}$ The possibility of meningitis should be considered in patients with nuchal rigidity, photophobia and headache or when a depressed level of consciousness does not improve promptly with hydration and blood sugar reduction. Cerebrospinal fluid glucose is not sensitive in diagnosing meningitis in hyperglycemic patients, though a value of $<5.55$ $\mathrm{mmol} / \mathrm{L}(100 \mathrm{mg} / \mathrm{dL})$ when the serum glucose is $>13.88$ $\mathrm{mmol} / \mathrm{L}(250 \mathrm{mg} / \mathrm{dL})$ suggests bacterial infection; a cerebrospinal fluid:serum glucose ratio $<0.31$ is also suggestive of bacterial meningitis in hyperglycemic patients. ${ }^{16}$ Pneumonia may be difficult to diagnose on chest radiograph in dehydrated patients, but pulmonary infiltrates and progressive hypoxemia typically develop with hydration in those with active pneumonitis. Table 2 lists common precipitating factors of DKA and HHS.

Discontinuation of hypoglycemic medications and/ or inadequate insulin therapy in established type 1 diabetic patients commonly lead to DKA, ${ }^{7}$ including in those using insulin pumps. Age also plays an 
Table 2. Precipitating causes of Diabetic Ketoacidosis and Hyperglycemic Hyperosmolar State

\begin{tabular}{|c|c|}
\hline DKA & HHS \\
\hline Noncompliance & Noncompliance \\
\hline Acute illness & Acute illness \\
\hline Infection $30-40 \%$ & Infection $32-60 \%$ \\
\hline Viral syndrome & Pneumonia \\
\hline Urinary tract infection & Urinary tract infection \\
\hline Pelvic inflammatory disease & Sepsis \\
\hline Pneumonia & Cerebrovascular accident \\
\hline Mucormycosis & Myocardial infarction \\
\hline Malignant otitis externa & Acute pancreatitis \\
\hline Periodontal abscess & Pulmonary embolus \\
\hline Dental infection & Intestinal obstruction \\
\hline Cytomegalovirus infection & Mesenteric thrombosis \\
\hline Cerebrovascular accident & Peritoneal dialysis \\
\hline Myocardial infarction & Renal failure \\
\hline Acute pancreatitis & Heat stroke \\
\hline New-onset diabetes (20-25\%) & Hypothermia \\
\hline Drugs & Subdural hematoma \\
\hline Clozapine & Severe burns \\
\hline Cocaine & Rhabdomyolysis \\
\hline Lithium & Endocrine \\
\hline Terbutaline & Acromegaly \\
\hline Indinavir & Thyrotoxicosis \\
\hline Olanzapine & Cushing's syndrome \\
\hline Orlistat & Drugs \\
\hline alpha-Interferon & Calcium channel blockers \\
\hline Highly active antiretroviral therapy & y Chlorpromazine \\
\hline Corticosteoid & Chlorthalidone \\
\hline \multirow[t]{11}{*}{ Malfunction of insulin pump } & Cimetidine \\
\hline & Loxapine \\
\hline & Olanzapine \\
\hline & Pentaidne \\
\hline & Phenytoin \\
\hline & Propranolol \\
\hline & Steroids \\
\hline & alpha-Asparaginase \\
\hline & Ethacrynic acid \\
\hline & Total parenteral nutrition \\
\hline & New-onset diabetes \\
\hline
\end{tabular}

DKA: diabetic keto acidosis; HHS: hyperglycemic hyperosmolar state important role: for example, amongst type 1 diabetic patients, teenagers and adolescents, for various reasons related to their lifephase, are notoriously less compliant with their insulin regimen. Correct usage is also critical. More than 375,000 people in the U.S. use insulin pumps to treat their type 1 diabetes, while almost 17,000 adverse events associated with their use were reported from 2006 to $2008 .{ }^{17}$ Pump malfunction, tube leakage, use of outdated insulin, pump exposure to excessive heat or sunlight, catheter clogging or dislodgement, or infusion site infection-especially when the catheter and tubing set are left unchanged for more than 3 days - can result in interruption of insulin delivery. ${ }^{18,19}$

It is important to note that DKA can also develop in type 2 diabetics depending on the patient's ability to secrete insulin (= insulin dependency) and nutritional status (i.e. starvation, see paragraph further below "starvation ketosis").

Several other conditions can precipitate hyperglycemic emergencies. Acute pancreatitis may be accompanied by DKA $;{ }^{18}$ while serum amylase may be elevated without pathologic significance, serum lipase is more specific for active pancreatic inflammation. ${ }^{21}$ Drugs affecting carbohydrate metabolism (e.g. corticosteroids, second generation antipsychotic agents) can precipitate either emergency. ${ }^{22}$ Cocaine abuse causes recurrent DKA via several mechanisms, including therapeutic noncompliance, stimulation of adrenal release of epinephrine and norepinephrine and increased release of other counter regulatory hormones. ${ }^{23,24}$ Cytomegalovirus infection, ${ }^{25,26}$ protease inhibitor treatment, ${ }^{27,28}$ and highly active antiretroviral therapy (via immune restoration) may precipitate DKA in HIV-infected patients. ${ }^{29}$ Acute myocardial infarction, stroke, major trauma and other severe/ acute illnesses may precipitate either DKA or HHS. ${ }^{3}$

\section{Differential Diagnosis}

Other causes of metabolic acidosis and ketosis must be differentiated from DKA.

Acute renal failure accounts for $\sim 5-7 \%$ of all adult hospitalizations. ${ }^{30,31}$ It shares the common feature of an elevated anion gap metabolic acidosis, but can be easily differentiated from DKA by the absence of hyperglycemia or ketonemia. Conversely, severe 
cases of DKA or HHS can lead to prerenal azotemia and secondary acute kidney injury.

Uremic acidosis, characterized by an extremely high blood urea nitrogen, often $>71.4 \mathrm{mmol} / \mathrm{L}(200 \mathrm{mg} /$ $\mathrm{dL})$ and creatinine $>884 \mathrm{umol} / \mathrm{L}(10 \mathrm{mg} / \mathrm{dL})$, causes acidosis via retention of anionic solutes in the patient with chronic kidney disease. The $\mathrm{pH}$ and anion gap are often only mildly abnormal, however, and blood sugar is typically normal. Uremia typically develops when creatinine clearance falls to $<0.1669 \mathrm{ml} / \mathrm{s}(10$ $\mathrm{mL} / \mathrm{min}$ ) in irreversible renal disease. . $2,33^{2}$

Lactic acidosis occasionally contributes to metabolic acidosis in patients hospitalized for either uncomplicated diabetes or DKA. ${ }^{34}$ It occurs in the setting of decreased tissue oxygen delivery, triggering non-oxidative metabolism of glucose to lactic acid. When co-existent with DKA, the anion gap typically exceeds that attributable to lactate alone. Lactic acidosis, with a serum lactate $\geq 5 \mathrm{mmol} / \mathrm{L}(45 \mathrm{mg} / \mathrm{dL})$, accompanies DKA and HHS when severe volume depletion compromises cardiac output; pre-existent cardiovascular disease increases this risk. Underlying liver disease (with reduced lactate clearance) and sepsis may also be accompanied by more frequent/ severe lactic acidosis in hyperglycemic emergencies. Therapy is directed at optimizing tissue perfusion and treating underlying conditions. ${ }^{23,32}$

Starvation ketosis, caused by insufficient carbohydrate availability, results in physiologically appropriate lipolysis and ketogenesis to provide fuel substrates. Blood glucose and arterial $\mathrm{pH}$ are usually normal and the anion gap is at most mildly elevated. Although ketonuria may be pronounced, ketonemia is typically modest. ${ }^{23,32}$

Alcoholic ketosis is seen in patients who abuse alcohol chronically and for whom ethanol has been the predominant caloric source for days or weeks. Ketosis occurs when alcohol and caloric intake decrease suddenly. Usually, patients are normoglycemic or hypoglycemic on presentation, although mild hyperglycemia is occasionally present. ${ }^{32}$

Toxic ingestions can be differentiated by history and laboratory studies. Salicylate, methanol and ethylene glycol each produce an elevated anion gap metabolic acidosis without hyperglycemia or ketosis. Methanol and ethylene glycol will also cause a serum osmolal gap. ${ }^{23,32}$ Measuring suspected drug/toxin concentrations when the index of suspicion is high can confirm the diagnosis of acute intoxication. ${ }^{35-38}$

Non-anion gap metabolic acidosis is characterized by a low serum bicarbonate concentration (via gastrointestinal or renal losses) with subsequent chloride retention. Diarrhea and renal tubular acidosis are frequent causes of this condition, which can also occur with carbonic anhydrase inhibitor therapy. Rapid dilution of plasma bicarbonate by infused saline can result in a non-anion gap metabolic acidosis as well..$^{39,40}$ Diabetic ketoacidosis can be easily differentiated from this condition by the presence of an increased anion gap and hyperglycemia. Hypoalbuminemia can affect the apparent anion gap, since albumin is a negatively charged protein contributing 50-60\% to the "normal" anion gap of 10-15; the calculated anion gap should be corrected by adding 2.5 for every $10 \mathrm{~g} / \mathrm{L}(1 \mathrm{~g} / \mathrm{dL})$ that the albumin is below the normal value of $40 \mathrm{~g} / \mathrm{L}$ $(4 \mathrm{~g} / \mathrm{dL})$ to determine whether excessive abnormal anions are present. ${ }^{41-43}$

\section{TREATMENT}

Treatment of both DKA and HHS focuses on replacing volume deficits, correcting electrolytes, reversing the acid-base imbalance, normalizing blood glucose and treating precipitating factors to prevent recurrence and hasten recovery. Successful treatment of either condition requires frequent monitoring of clinical and laboratory parameters. A flow sheet recording laboratory results, vital signs and fluid balance is helpful in monitoring progress and adjusting therapy. ${ }^{23}$ A systematic approach to treatment should achieve clinical stability within 12-36 hours. A sample protocol for managing adult patients with hyperglycemic emergencies is summarized in Figure 1.

Additionally, endocrinology/diabetes team consultations may result in shorter hospital stays, fewer medical procedures and lower medical costs, ${ }^{44,45}$ and should be considered for most patients.

\section{Fluids}

Both conditions are volume depletion states, with water deficits varying widely but averaging $6 \mathrm{~L}$ in DKA and 9 L in HHS (Table 1). The goal of fluid resuscita- 


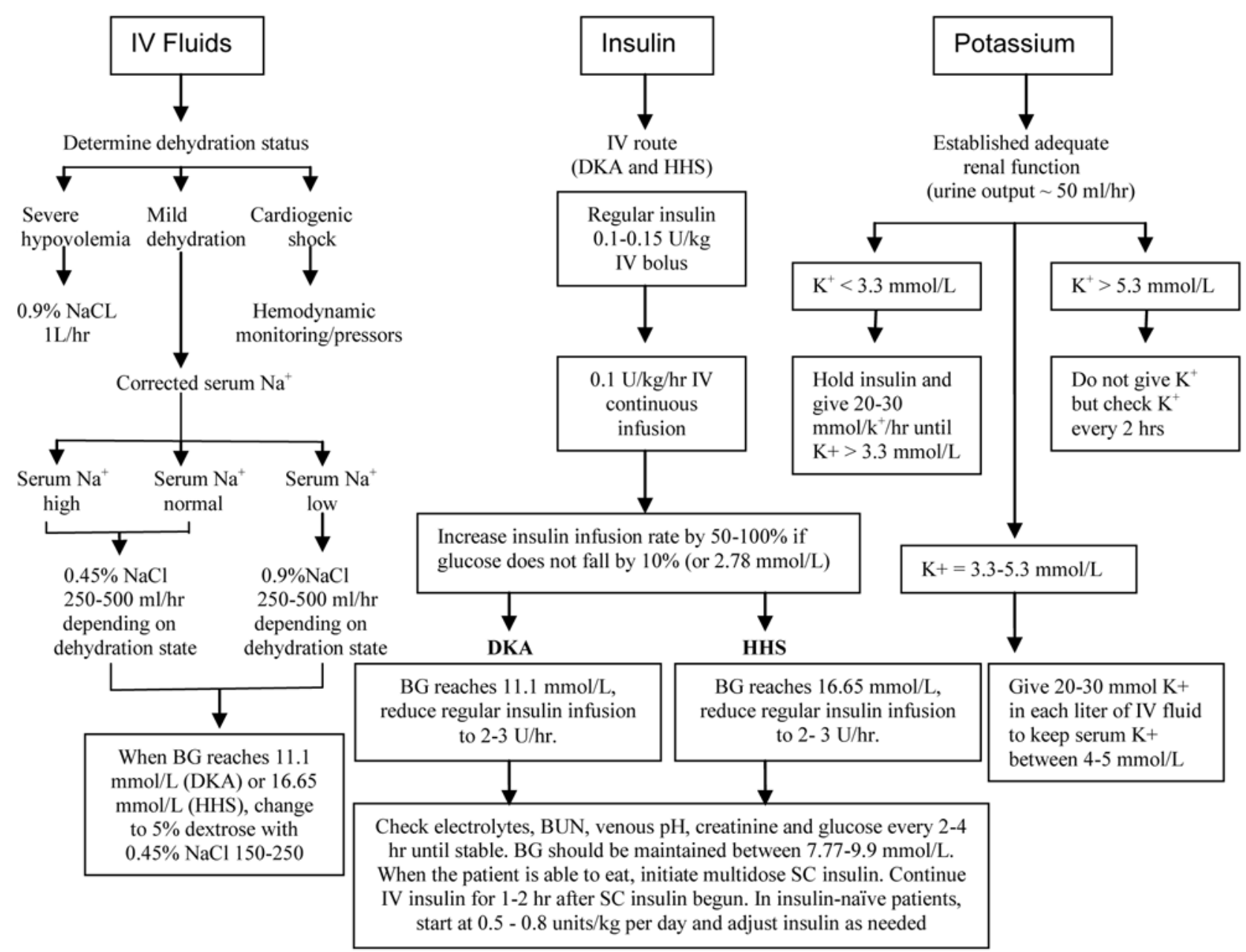

Figure 1. Protocol for management of adult patients with DKA or HHS (modified from reference 3, 5 and 47).

tion is to replace half of the estimated water deficit over the first 12-24 hours. In hypotensive patients, aggressive fluid resuscitation with isotonic saline should be continued until blood pressure normalizes.

Hyperglycemia can reduce serum sodium by causing an osmotically driven shift of water from intracellular to extracellular compartments. Although previous prediction models estimated that each $5.5 \mathrm{mmol} / \mathrm{L}(100$ $\mathrm{mg} / \mathrm{dL}$ ) increment in glucose above normal resulted in an expected decrease of $1.6 \mathrm{mmol} / \mathrm{L}(1.6 \mathrm{mEq} / \mathrm{L})$ in measured serum sodium, ${ }^{46}$ a subsequent study suggests that $2.4 \mathrm{mmol} / \mathrm{L}(2.4 \mathrm{mEq} / \mathrm{L})$ per $5.5 \mathrm{mmol} / \mathrm{L}$ $(100 \mathrm{mg} / \mathrm{dL})$ glucose increment is more accurate. ${ }^{47}$

The initial fluid of choice is isotonic saline, generally given for the first 4 hours of therapy, to expand interstitial and intravascular volume (Table 3). Sub- sequent fluid replacement depends upon the state of hydration, serum electrolytes and urine output. Fluid resuscitation should be individualized according to the patient's degree of dehydration, mental status and underlying diseases such as congestive heart failure. Glucose, an osmotic diuretic, may produce a high urine output even in severely dehydrated patients. The threshold for glycosuria in healthy adults occurs at plasma glucose concentration of approximately $9.99 \mathrm{mmol} / \mathrm{L}(180 \mathrm{mg} / \mathrm{dL})$, though adults with long-standing diabetic nephropathy may have considerably higher thresholds; hence, urine output should not be considered a reliable predictor of volume status in hyperglycemic states. ${ }^{48}$ When patients are hypernatremic or eunatremic, $0.45 \%$ sodium chloride infusion is an appropriate replacement for free water lost by glycosuric diuresis. Dextrose, $5 \%$ 
Table 3. Suggested initial rate of fluid repletion in hyperglycemic emergencies*

\begin{tabular}{ll}
\hline Hours & Volume \\
\hline $1^{\text {st }}$ hour & $1,000-2,000 \mathrm{~mL}$ \\
$2^{\text {nd }}$ hour & $1,000 \mathrm{~mL}$ \\
$3^{\text {rd }}-5^{\text {th }}$ hours & $500-1,000 \mathrm{~mL} /$ hour \\
$6^{\text {th }}-12^{\text {th }}$ hours & $250-500 \mathrm{~mL} /$ hour \\
\hline
\end{tabular}

*average replacement after initial hemodynamic resuscitation with normal saline when indicated

in $0.45 \%$ normal saline, should be considered when blood glucose falls to $<11.1-13.88 \mathrm{mmol} / \mathrm{L}(200-250$ $\mathrm{mg} / \mathrm{dL})$ in $\mathrm{DKA}^{7,32}$ and $<16.65 \mathrm{mmol} / \mathrm{L}(300 \mathrm{mg} / \mathrm{dL})$ in $\mathrm{HHS}^{7,10}$ (see below).

\section{Insulin and Glucose}

A continuous intravenous infusion of regular insulin lowers the serum glucose concentration (by decreasing hepatic glucose production and increasing tissue glucose uptake) and arrests ketone production (by reducing lipolysis and glucagon secretion). The only indication for delaying insulin therapy is a serum potassium $<3.3 \mathrm{mmol} / \mathrm{L}(3.3 \mathrm{mEq} / \mathrm{L})$, since insulin will exacerbate hypokalemia by facilitating potassium transport into cells. Although an initial bolus dose of 10 units regular insulin (0.1-0.15 units/ $\mathrm{kg}$ body weight) is recommended by most authors, ${ }^{32,49}$ recent data from almost 200 DKA patients suggest this may confer no additional clinical benefit when the infusion dose is adequate (0.1-0.14 units/ $/ \mathrm{kg} /$ hour for either DKA or HHS). ${ }^{50,51}$ The administration rate should be increased by $50-100 \%$ if glucose does not fall $\geq 10 \%$ or $2.78 \mathrm{mmol} / \mathrm{L}(50 \mathrm{mg} / \mathrm{dL})$ per hour, and decreased to 2-3 units/hour when glucose falls to 11.1 $\mathrm{mmol} / \mathrm{L}(200 \mathrm{mg} / \mathrm{dL})$ in DKA or $13.88 \mathrm{mmol} / \mathrm{L}(250$ $\mathrm{mg} / \mathrm{dL}$ ) in HHS., ${ }^{3,7}$ The serum glucose concentration should be maintained between 7.77-9.99 mmol/L (140$180 \mathrm{mg} / \mathrm{dL}$ ) for ICU patients and between 5.55-9.99 $\mathrm{mmol} / \mathrm{L}(100-180 \mathrm{mg} / \mathrm{dL})$ for patients admitted to general medical wards. ${ }^{7,52-56}$ Generally, 12-24 hours of intravenous insulin treatment is necessary to clear ketones from the circulation after hyperglycemia is corrected.

Once the patient can eat, a change to subcutaneous insulin should be considered. A multiple-dose subcutaneous combination regimen with long-acting (e.g. glargine) and rapid-acting (e.g. Lispro, aspart or glulisine) insulins is preferred, as it results in less hypoglycemia and provides a more physiologic pattern of control than other regimens. In insulin-naïve patients, a starting dose of 0.5-0.8 units $/ \mathrm{kg}$ body weight per day, adjusted based on blood glucose response, is a tested approach. ${ }^{57} \mathrm{~A}$ transition to subcutaneous glargine and glulisine after resolution of DKA resulted in similar glycemic control, but with a lower risk of hypoglycemia, than a regimen of NPH and regular insulin in a study of 74 patients with DKA. ${ }^{58}$ Intravenous infusion insulin should be continued for 1-2 hours after the first subcutaneous dose is given to ensure adequate plasma insulin levels are maintained, thus avoiding recurrent hyperglycemia or ketoacidosis. ${ }^{23}$

Subcutaneous rapid-acting insulin analogs offer an efficacious and cost-effective alternative to continuous intravenous infusions. ${ }^{59-61}$ Studied protocols use subcutaneous rapid-acting insulin $(0.2 \mathrm{units} / \mathrm{kg}$ initially) followed by 0.1 unit $/ \mathrm{kg}$ every hour, or an initial dose of 0.3 units $/ \mathrm{kg}$ followed by 0.2 units $/ \mathrm{kg}$ every 2 hours, until blood glucose is $\leq 13.88 \mathrm{mmol} / \mathrm{L}$ $(250 \mathrm{mg} / \mathrm{dL})$; the insulin dose is then decreased by half (to 0.05 or $0.1 \mathrm{unit} / \mathrm{kg}$, respectively) every $1-2$ hours until resolution. This approach is not widely used for many reasons, including titration difficulties with longer half-life preparations, requirement for hourly nursing interventions and lack of staff experience compared to that with standard insulin infusions.

\section{Potassium}

Despite a total body potassium deficit resulting from the glycosuric osmotic diuresis, serum potassium is usually normal or elevated upon initial presentation because of proteolysis, hypertonicity and insulin deficiency. ${ }^{12,62}$ Metabolic acidosis resulting from organic acids (e.g. lactic, $\beta$-hydroxybutyric acid) is much less often associated with potassium displacement out of cells, as cell membranes are permeable to these acids. ${ }^{62}$

The goal of replacement is to maintain potassium levels at 4-5 mmol/L (4-5 mEq/L). Insulin treatment and volume expansion both act to lower serum potassium, often abruptly. To prevent hypokalemia, replacement should be initiated when serum potassium falls below $5 \mathrm{mmol} / \mathrm{L}(5 \mathrm{mEq} / \mathrm{L})$, or when $<4$ $\mathrm{mmol} / \mathrm{L}(4 \mathrm{mEq} / \mathrm{L})$ in patients with a urine output $>50$ $\mathrm{mL} /$ hour (unless hypokalemic electrocardiographic 
changes develop). Adding 20-30 mmol (20-30 mEq) potassium to each liter of infused fluid is usually an adequate replacement strategy, but additional doses may be necessary. $3,7,32$

\section{Bicarbonate}

Serum bicarbonate is always low in DKA; however, because ketoacid and lactate anions are metabolized to bicarbonate with effective therapy, bicarbonate administration is rarely needed and is in fact highly controversial. ${ }^{63}$ Exogenous bicarbonate may precipitate hypokalemia, reduce tissue oxygen uptake, increase the risk of cerebral edema and delay resolution of ketosis. ${ }^{63-66}$ It should be reserved for patients with severe acidosis (arterial $\mathrm{pH}<6.9$ ), or when $\mathrm{pH}$ is $<7.1$ and hemodynamic instability or hyperkalemic electrocardiographic changes are present. ${ }^{7,32}$ In these circumstances, $100 \mathrm{mmol}(100 \mathrm{mEq})$ or $100 \mathrm{~mL}$ of sodium bicarbonate mixed in $400 \mathrm{~mL}$ sterile water and infused at $200 \mathrm{~mL} /$ hour ( $40 \mathrm{mmol} /$ hour) is usually sufficient, though re-dosing every 2 hours may be considered until $\mathrm{pH}$ exceeds 7.0.7,32 Potassium replacement should be considered before administering bicarbonate, or KCL should be added in the bicarbonate solution at $40 \mathrm{mmol}(40 \mathrm{mEq}) \mathrm{KCl} / \mathrm{L}$ to avoid precipitous hypokalemia., ${ }^{7,32}$

\section{Phosphate}

Though phosphate is also depleted in DKA, patients usually present with a normal or elevated serum phosphate level which falls rapidly with insulin therapy. ${ }^{7,32}$ Routine phosphate repletion confers no proven benefit on clinical outcome, ${ }^{32-68}$ but most authorities recommend replacement when severe $<0.323 \mathrm{mmol} / \mathrm{L}$ $(1 \mathrm{mg} / \mathrm{dL})$ or when evidence of clinical compromise (hemolysis, refractory acidosis, reduced cardiac output, respiratory muscle weakness, rhabdomyolysis, central nervous system depression, seizures, coma or acute renal failure) is present. ${ }^{7,32,69,70}$ In these settings, replacement with doses of $20-40 \mathrm{mmol}$ potassium or sodium phosphate intravenously, at a maximum rate of $20 \mathrm{mmol} /$ hour, appears safe and effective. ${ }^{70,71}$ Oral phosphate may be administered subsequently, or primarily in less severe deficiencies; recommended doses are 80-110 mmol (2.5-3.5 g) daily in 2-3 divided doses for patients tolerating oral intake. As intravenous phosphate administration may lead to hypocalcemia and hypomagnesemia, serum levels of both should be measured, and replacement given as needed, prior to initiating phosphate replacement. ${ }^{7,32,70}$

Studies to date have not demonstrated any value of phosphate replacement in patients with HHS. Physicians may follow the same treatment principles as in DKA patients with severe hypophosphatemia if replacement is considered..$^{10}$

\section{Monitoring}

Patients with mild or uncomplicated DKA can be managed in non-ICU telemetry units and expect outcomes similar to those treated in an ICU setting. ${ }^{72-76}$ As age is an independent predictor of mortality in patients with $\mathrm{HSS}^{2}$ and HHS is more common in elderly patients with type 2 diabetes and significant co-morbidities, it is reasonable that all such patients be admitted to an ICU. ${ }^{12}$

General recommendations for ongoing laboratory monitoring include hourly blood glucose levels for the first 4-6 hours, and at 2 hour intervals subsequently; electrolyte and $\mathrm{CO}_{2}$ content (every 2-4 hours) and blood urea nitrogen and creatinine levels (every 4 hours) should also be monitored until stable. Fluid intake and output should be accurately recorded. ${ }^{3}$ Since serum bicarbonate and anion gap are good indices of therapeutic response, repeated assessments of arterial blood gases or serum or urine ketones are usually unnecessary. As $\beta$-hydroxybutyrate converts to acetoacetate, and conventional (nitroprusside) testing detects only acetoacetate and acetone, standard ketone levels during therapy may appear unchanged or erroneously high even when treatment has successfully arrested ketogenesis. ${ }^{32}$ When acidosis begins to resolve, the anion gap falls to near normal and the response to glycemic therapy becomes predictable, it is reasonable to reduce laboratory test frequency. ${ }^{32}$ Persistent acidosis that does not respond to treatment may be caused by sepsis, concomitant illness or inadequate insulin dosing and mandates further evaluation and intervention. ${ }^{3,32}$

\section{Complications of Therapy}

Hypoglycemia and hypokalemia are the two most common complications seen during treatment of DKA and HHS. ${ }^{7}$ Hyperchloremic metabolic acidosis is a highly predictable consequence of sodium chloride loading during volume resuscitation, appears to be 
of no clinical consequence and resolves spontaneously within several days. ${ }^{12}$ Cerebral edema occurs in $0.3-1 \%$ of children with DKA but is very rare in adults ${ }^{7,77}$ and its mechanism is debated. ${ }^{7,77-83}$ Other reported life-threatening complications include adult respiratory distress syndrome, hydrostatic pulmonary edema, bronchial mucous plugging, ischemic intestinal necrosis and arterial and venous thromboses; ${ }^{32,84-88}$ standard low-dose unfractionated heparin or low molecular weight heparin prophylaxis is reasonable adjunctive therapy when no contra-indications are present. $^{32,87}$

\section{Prevention of recurrences}

Hyperglycemic emergencies are usually preventable. Infection and medical noncompliance are the two most common causes of DKA and HHS. Established patients should be educated on how to manage their diabetes during stress or infection; this "sick-day management" includes never omitting insulin, preventing dehydration and hypoglycemia, monitoring blood glucose frequently, testing for ketosis, administering supplemental rapid-acting insulin doses according to prescribed guidelines, treating underlying triggers early and aggressively and having frequent contact with their diabetes health care team to evaluate their acute condition. ${ }^{32,89}$ Patient education and 24-hour access to care are cornerstones of preventive therapy..$^{90}$

Teenagers and adolescents with type 1 diabetes should be advised to not ignore the fact that they have a life-threatening disease that requires insulin to avoid repetitive hospital admissions for DKA. The transition period from adolescence to adulthood of these patients is very important, especially when considering the infrastructure (health insurance) of certain countries, with patients often being lost because of their inability to pay the medical bills. It is unclear whether this explains in part why the data from the CDC over the period of 25 years (1980-2005) showed a rise from 62,000 hospital discharges per year (1980) in the United States to 120,000 hospital discharges per year (2005). ${ }^{1}$ On the other hand, despite this rise in incidence, better understanding of the pathogenesis of DKA and HHS and the implementation of treatment guidelines have led to a decline in mortality rates for these conditions. ${ }^{90}$

Elderly patients with limited mobility or living in a nursing home may be unable to replace excessive fluid losses during inter-current illnesses and are at particularly high risk for developing HHS. Educating caregivers to recognize signs and symptoms of worsening hyperglycemia and dehydration can reduce the incidence and severity of HHS. For patients who live alone, family or friends should check daily to assess for changes in mental status or signs of dehydration.

\section{SUMMARY}

Though the hyperglycemic emergencies DKA and HHS are life-threatening, with mortality rates up to $20 \%$ (for HHS), they are largely preventable conditions. A diligent search for precipitating causes contributes to better outcomes and fewer recurrences, while an organized, methodical and aggressive approach to treatment can achieve clinical stability in 1236 hours. Patient education and easy access to health care resources are essential to prevent recurrences.

\section{No conflict of interest or financial support declared.}

\section{REFERENCES}

1. Centers for Disease Control and Prevention (CDC), 2008 Number (in Thousands) of Hospital Discharges with Diabetic Ketoacidosis as First-Listed Diagnosis, United States, 1980-2005. Available online. http://www. cdc.gov/diabetes/statistics/dkafirst/diabetes_complications/fig1.htm. Accessed October 8, 2011.

2. MacLsaac RJ, Lee RY, McNeil KJ, et al, 2002 Influence of age on the presentation an outcome of acidotic and hyperosmolar diabetic emergencies. Intern Med J 32: 379-785.

3. Ennis ED, Kreisberg RA 2003 Diabetic ketoacidosis and the hyperglycemic hyperosmolar syndrome. In: LeRoith D, Taylor SI, Olefsky JM (eds) Diabetes Mellitus: A Fundamental and Clinical Text 3rd edn, Lippincott Williams \& Wilkins, Philadelphia; pp, 627-641.

4. Isotani H, Asaka S, Kameoka K, et al, 1997 Hyperglycemic hyperosmolar syndrome associated with severe ketosis in Japanese woman. Horm Metab Res 29: 360-361.

5. Greco AV, Ghirlanda G, Altomonte L, et al, 1981 Somatostatin and insulin infusion in the management of diabetic ketoacidosis. Horm Metab Res 13: 310-314.

6. Nugent BW, 2005 Hyperosmolar hyperglycemic state. Emerg Med Clin North Am 23: 629-648.

7. Kitabchi AE, Miles JM, Umpierrez GE, et al, 2009 Hyperglycemic crisis in adult patients with diabetes. Diabetes Care 32: 1335-1343.

8. Kitabchi AE, Umpierrez GE, Murphy MB, et al, 2006 Hyperglycemic crises in adult patients with diabetes: 
a consensus statement from the American Diabetes Association. Diabetes Care 29: 2739-2748.

9. Morris LR, Kitabchi AE, 1980 Efficacy of low-dose insulin therapy for severely obtunded patients in diabetic ketoacidosis. Diabetes Care 3: 53-56.

10. Stoner GD, 2005 Hyperosmolar hyperglycemic state. Am Fam Physician 71: 1723-1730.

11. Matz R, 1999 Management of hyperosmolar hyperglycemic syndrome. Am Fam Physician 60: 1468-1476.

12. Kitabchi AE, Umpierrez GE, Murphy MB, et al 2001 Management of hyperglycemic crisis in patients with diabetes. Diabetes Care 24: 131-153.

13. Wachtel TJ, Tetu-Mouraddjian LM, Goldman LD, et al, 1991 Hyperosmolarity and acidosis in diabetes mellitus: A three year experience in Rhode Island. J Gen Intern Med 6: 495-502.

14. Burris AS, 1986 Leukemoid reaction associated with severe diabetic ketosis. South Med J 79: 647-648.

15. Esper AM, Moss M, Martin GS, 2009 The effect of diabetes mellitus on organ dysfunction with sepsis: an epidemiological study. Crit Care 13: R18.

16. Powers WJ, 1981 Cerebrospinal fluid to serum glucose ratios in diabetes mellitus and bacterial meningitis. Am J Med 71: 217-220.

17. MassDevice staff, 2010 FDA investigates reports of insulin pump problems. Available online. http://www. massdevice.com/news/fda-investigates-reports-insulinpump-problems. Accesses October 8, 2011.

18. Hoogma RP, Schumicki D, 2006 Safety of insulin glulisine when given by continuous subcutaneous infusion using an external pump in patients with type 1 diabetes. Horm Metab Res 38: 429-433.

19. Hunger-Dathe W, Braun A, Müller UA, et al, 2003 Insulin pump therapy in patients with type 1 diabetes mellitus: results of the nationwide quality circle in Germany (ASD) 1999-2000. Exp Clin Endoclinol Diabetes 111: 428-434.

20. Nair S, Yadav D, Pitchumoni CS, 2000 Association of diabetic ketoacidosis and acute pancreatitis: observations in 100 consecutive episodes of DKA. Am J Gastroenterol 95: 2795-2800.

21. Chase CW, Barker DE, Russell WL, et al, 1996 Serum amylase and lipase in the evaluation of acute abdominal pain. Am Surg 62: 1028-1033.

22. Yazici KM, Erbas T, Yazici AH, 1998 The effect of clozapine on glucose metabolism. Exp Clin Endocrinol Diabetes 106: 475-477.

23. Kitabchi, AE, Nyenwe EA, 2006 Hyperglycemic crisis in diabetes mellitus: Diabetic ketoacidosis and hyperosmolar state. Endocrinol Metab Clin North Am 35: 725-751.

24. Warner AE, Greene GS, Buchsbaum MS, et al, 1998 Diabetic ketoacidosis associated with cocaine use. Arch Intern Med 158: 1799-1802.

25. Evans EM, Nye F, Beeching NJ, et al, 2005 'Disappearing diabetes' - resolution of apparent type 1 diabetes in a patient with AIDS and cytomegalovirus (CMV) infection. Diabet Med 22: 218-220.

26. Izumi K, 2009 Diabetic ketoacidosis with cytomegalovirus-associated colitis. Intern Med 48: 343-346.

27. Besson C, Jubault V, Viard JP, et al, 1998 Ketoacidosis associated with protease inhibitor therapy. AIDS 12: 1399-1400.

28. Kan VL, Nylen ES, 1999 Diabetic ketoacidosis in an HIV patient: A new mechanism of HIV protease-inhibitorinduced glucose intolerance. AIDS 13: 1987-1989.

29. Takarabe D, Rokukawa Y, Takahashi Y, et al, 2010 Autoimmune diabetes in HIV-infected patients on highly active antiretroviral therapy. J Clin Endocrinolol Metab 95: 4056-4060.

30. Argarawal M, Swartz R, 2000 Acute renal failure. Am Fam Physician 61: 2077-2088.

31. Lewington A, Kanagasundaram S, 2011 Clinical Practice Guidelines: Acute Kidney Injury. Available online. http://www.renal.org/Libraries/Guidelines/Acute_Kidney_Injury_-_Final_Draft_08_January_2011.sflb.ashx Accessed October 8, 2011.

32. Eisenbarth GS, Polonsky KS, Buse JB 2008 Acute diabetic emergencies: Diabetic ketoacidosis. In: Kronenberg HM, Melmed S, Polonsky KS et al (eds). Williams Textbook of Endocrinology, 11th edn, Saunders Elsevier, Pennsylvania; pp, 1407-1416.

33. Vanholder R, De Smet R, Glorieux G, et al, 2003 Review on uremic toxins: classification, concentration, and interindividual variability. Kidney Int 63: 1934-1943.

34. Watkins PJ, Smith JS, Fitzgerald MG, et al, 1969 Lactic acidosis in diabetes. Br Med J 1: 744-747.

35. Samlan SR, Jordan MT, Chan SB, et at, 2008 Tinitus as a measure of salicylate toxicity in the overdose setting. West J Emerg Med 9: 146-149.

36. Chyka PA, Erdman AR, Christianson G, et al, 2007 Salicylate poisoning: an evidence-based consensus guideline for out-of-hospital management. Clin Toxicol 45: 95-131.

37. Mégarbane B, Borron SW, Baud FJ, 2005 Current recommendations for treatment of severe toxic alcohol poisonings. Intensive Care Med 31: 189-195.

38. Brent J, 2010 Fomepizole for the treatment of pediatric ethylene and diethylene glycol, butoxyethanol, and methanol poisonings. Clin Toxicol 48: 401-406.

39. Eisenhut M, 2006 Causes and effects of hyperchloremic acidosis. Crit Care 10: 413.

40. Walmsley RN, White GH, 1985 Normal "anion gap" (hyperchloremic) acidosis. Clin Chem 31: 309-313.

41. Charles JC, Heilman RL, 2005 Metabolic acidosis. Hosp Physician 41: 37-42.

42. Walmsley RN, White GH, 1985 Normal "Anion Gap" (Hyperchloremic) Acidosis. Clin Chem 31: 309-313.

43. Emmett M, Narins R, 1997 Clinical use of the anion gap. Medicine (Baltimore) 56: 38-54.

44. Levetan CS, Salas JR, Wilets JF et al, 1995 Impact of endocrine and diabetes team consultation on hospital length of stay for patients with diabetes. Am J Med 99: 22-28. 
45. Levetan CS, Passaro MD, Jablonski KA, et al, 1999 Effect of physician specialty on outcomes in diabetic ketoacidosis. Diabetes Care 22: 1790-1795.

46. Katz MA, 1973 Hyperglycemia induced hyponatremia - calculation of expected serum sodium depression. $\mathrm{N}$ Engl J Med 289: 843-844.

47. Hillier TA, Abbott RD, Barrett EJ, 1999 Hyponatraemia: evaluating the correction factor for hyperglycemia. Am J Med 106: 399-403.

48. Cowart SL, Stachura ME 1990 Glucosuria. In: Walker HK, Hall WD, Hurst JW (eds). Clinical Methods: The History, Physical, and Laboratory Examinations, 3rd edn, Butterworths, Boston; pp, 653-657.

49. Wyckoff J, Abrahamson MJ 2005 Diabetic ketoacidosis and hyperosmolar hyperglycemic state. In: Kahn CR, Weir GC, King GL et al (eds). Joslin's Diabetes Mellitus, 14th edn, Lippincott Williams \& Wilkins, Philadelphia; pp, 887-899.

50. Goyal N, Miller JB, Sankey SS, et al, 2010 Utility of initial bolus insulin in the treatment of diabetic ketoacidosis. J Emerg Med 38: 422-427.

51. Kitabchi AE, Murphy MB, Spencer J, et al, 2008 Is a priming dose of insulin necessary in a low-dose insulin protocol for the treatment of diabetic ketoacidosis? Diabetes Care 31: 2081-2085.

52. American Diabetes Association, 2009 Diabetes experts issue new recommendations for inpatient glycemic control - Call for systemic changes in Hospitals Nationwide. Available online. http://www.diabetes.org/ for-media/2009/diabetes-experts-issue-new-2009.html. Accessed April 5, 2011.

53. The NICE-SUGAR Study Investigators, 2009 Intensive versus conventional glucose control in critically ill patients. N Engl J Med 360: 1283-1297.

54. Krinsley JS, 2006 Glycemic control, diabetic status, and mortality in a heterogeneous population of critically ill patients before and during the era of intensive glycemic management: six and one-half years experience at a University-Affiliated Community Hospital. Semi Thorac Cardiovasc Surg 18: 317-325.

55. Falciglia M, Freyberg RW, Almenoff PL, et al, 2009 Hyperglycemia-related mortality in critically ill patients varies with admission diagnosis. Crit Care Med 37: 3001-3009.

56. Randy MY, Johnson DJ, Patel BM, et al, 2005 Influence of individual characteristics on outcome of glycemic control in intensive care unit patients with or without Diabetes Mellitus. Mayo Clin Proc 80: 1558-1567.

57. Kitabchi AE, Umpierrez GE, Fisher JN, et al, 2008 Thirty years of personal experience in hyperglycemic crises: diabetic ketoacidosis and hyperglycemic hyperosmolar state. J Clin Endocrinol Metab 93: 1541-1552.

58. Umpierrez GE, Jones S, Smiley D, et al, 2009 Insulin analogs versus human insulin in the treatment of patients with diabetic ketoacidosis: a randomized controlled trial. Diabetes Care 32: 1164-1169.
59. Umpierrez GE, Latif K, Stoever J, et al, 2004 Efficacy of subcutaneous insulin lispro versus continuous intravenous regular insulin for the treatment of patients with diabetic ketoacidosis. Am J Med 117: 291-296.

60. Umpierrez GE, Cuervo R, Karabell A, et al, 2004 Treatment of diabetic ketoacidosis with subcutaneous insulin aspart. Diabetes Care 27: 1873-1878.

61. Della Manna T, Steinmetz L, Campos PR, et al, 2005 Subcutaneous use of a fast-acting insulin analog: An alternative treatment for pediatric patients with diabetic ketoacidosis. Diabetes Care 28: 1856-1861.

62. Peterson LN, Levi M 2002 Disorder of potassium and metabolism. In: Schrier RW (ed). Renal and electrolyte disordes, 6th edn, Lippincott Williams \& Wilkins, Philadelphia; pp, 171-215.

63. Viallon A, Zeni F, Lafond P, et al, 1999 Does bicarbonate therapy improve the management of severe diabetic ketoacidosis? Crit Care Med 27: 2690-2693.

64. Adrogue HJ, Wilson H, Boyd AE 3rd, et al, 1982 Plasma acid-base patterns in diabetic ketoacidosis. N Engl J Med 307: 1603-1610.

65. Okuda Y, Adrogue HJ, Field JB, et al, 1996 Counterproductive effects of sodium bicarbonate in diabetic ketoacidois in childhood. J Clin Endocriniol Metab 81: 314-320.

66. Foster DW, McGarry JD, 1982 The metabolic derangements and treatment of diabetic ketoacidosis. N Eng J Med 309: 159-169.

67. Fisher JN, Kitabchi AE, 1983 A randomized study of phosphate therapy in the treatment of diabetic ketoacidosis. J Clin Endocrinol Metab 57: 177-180.

68. Winter RJ, Harris CJ, Phillips LS et al, 1979 Diabetic ketoacidosis: induction of hypocalcemia and hypomagnesemia by phosphate therapy. Am J Med 67: 897-900.

69. Kreisberg RA, 1977 Phosphorus deficiency and hypophosphatemia. Hosp Pract 12: 121-128.

70. Geerse DA, Bindels AJ, Kuiper MA, et al, 2010 Treatment of hypophosphatemia in the intensive care unit: a review. Crit Care 14: R147.

71. Shiber JR, Mattu A, 2002 Serum phosphate abnormalities in the emergency department. J Emerg Med 23: 395-400.

72. Freire AX, Bridges L, Umpierrez GE, et al, 2005 Admission hyperglycemia and other risk factors as predictors of hospital mortality in a medical ICU population. Chest 128: 3109-3116.

73. Henriksen OM, Prahl JB, Røder ME, et al, 2007 Treatment of diabetic ketoacidosis in adults in Denmark: A national survey. Diabetes Res Clin Pract 77: 113-119.

74. Marinac JS, Mesa L, 2000 Using a severity of illness scoring system to assess intensive care unit admissions for diabetic ketoacidosis. Crit Care Med 28: 2238-2241.

75. Empierrez G, Smiley D 2006 Diabetic ketoacidosis and hyperglycemic hyperosmolar syndrome. In: Fonseca VA (ed). Clinical diabetes: translating research into practice, 1st edn, Saunders Elsevier, Philadelphia; pp, 101-106. 
76. Egol AB, Fromm RE, Guntupalli KK, et al, 1999 Guideline for ICU admission, discharge and triage. Crit Care Med 27: 633-638.

77. Haringhuizen A, Tjan DHT, Grool A, et al, 2010 Fatal cerebral oedema in adult diabetic ketoacidosis. Neth $\mathrm{J}$ Med 68: 35-37.

78. Glaser NS, Wootton-Gorges Sl, Marcin JP, et al, 2004 Mechanism of cerebral edema in children with diabetic ketoacidosis. J Pediatr 145: 164-171.

79. Abbott NJ, 2000 Inflammatory medicators and modulation of blood brain barrier permeability. Cell Mol Neurobiol 20: 131-147.

80. Glaser N, 2001 Cerebral edema in children with diabetic ketoacidosis. Curr Diab Rep 1: 41-46.

81. Yuen N, Anderson SE, Glaser N, et al, 2008 Cerebral blood flow and cerebral edema in rats with diabetic ketoacidosis. Diabetes 57: 2588-2894.

82. Seewi O, Vierzig A, Roth B, et al, 2010 Symptomatic cerebral oedema during treatment of diabetic ketoacidosis: effect of adjuvant octreotide infusion. Diabetol Metab Syndr 2: 56.

83. Edge JA, Jakes RW, Roy Y et al, 2006 The UK casecontrol study of cerebral oedema complicating diabetic ketoacidosis in children. Diabetologia 49: 2002-2009.

84. Brun-Buisson CJ, Bonnet F, Bergeret S, et al, 1985 Re- current high-permeability pulmonary edema associated with diabetic ketoacidosis. Crit Care Med 13: 55-56.

85. Brandstetter RD, Tamarin FM, Washington D, et al, 1987 Occult mucous airway obstruction in diabetic ketoacidosis. Chest 91: 575-578.

86. Hansen LA, Prakash UB, Colby TV, 1989 Pulmonary complications in diabetes mellitus. Mayo Clin Proc 64: 791-799.

87. Chiasson JL, Aris-Jilwan N, Bélanger R, et al, 2003 Diagnosis and treatment of diabetic ketoacidosis and the hyperglycemic hyperosmolar state. Can Med Assoc J 168: 859-866.

88. Ashrafi M, Hashemipour M, Moadab M, et al, 2007 Ischemic intestinal necrosis in a five-year-old girl with diabetic ketoacidosis. Arch Iran Med 10: 529-531.

89. Wilson JF, 2010 In Clinic. Diabetic ketoacidosis. Ann Intern Med 152: ITC1-14.

90. Toeller M, Buyken AE, Heitkamp G, et al, 1999 Prevalence of chronic complications, metabolic control and nutritional intake in type 1 diabetes: comparison between different European regions. EURODIAB Complications Study group. Horm Metab Res 31: 680-685.

91. Nyenwe EA, Kitabchi A. Evidence based management of hyperglycemic emergencies in diabetes mellitus. Diabetes Res Clin Pract 2011; Oct 4 epub ahead of print 